\title{
SKUBIOS MEDICINOS PAGALBOS PAIEŠKOS DELSIMAS SUSIRGUS ŪMINIU MIOKARDO INFARKTU
}

\author{
Tomas Tamošiūnas ${ }^{1}$, Renata Ruseckaite் ${ }^{1}$, Monika Laukyte் ${ }^{1}$, Ignẻ Bunevičiūte் ${ }^{2}$ \\ ${ }^{1}$ Vilniaus universiteto ligonine Santaros klinikos, ${ }^{2}$ Vilniaus universiteto Medicinos fakultetas
}

Raktažodžiai: ūminis miokardo infarktas, medicinos pagalbos paieškos delsimas, rizikos faktoriai.

\section{Santrauka}

Ūminis miokardo infarktas - viena iš pagrindiniu mirties priežasčių Lietuvoje. Gydymo sèkmè priklauso nuo to, kaip greitai atkuriama miokardo kraujotaka. Tyrimo tikslas - nustatyti, kiek pacientai delsia nuo ūminio miokardo infarkto simptomų atsiradimo iki sprendimo kreiptis medicinos pagalbos, identifikuoti rizikos faktorius, susijusius su delsimu. Atliktas prospektyvinis anketinis tyrimas individualiai apklausiant 100 pacientų, susirgusių ūminiu miokardo infarktu. Galutinejje analizėje dalyvavo 94. Pacientai suskirstyti ị dvi grupes pagal laiką, kuris praejo nuo simptomų atsiradimo iki sprendimo kreiptis medicinos pagalbos: I $(\mathrm{N}=56)$ grupe - $\leq 6$ val., II $(\mathrm{N}=38)$ grupé - $>6$ val. Darbo rezultatai: laiko, praejusio nuo simptomų atsiradimo iki sprendimo kreiptis medicinos pagalbos mediana $(25 ; 75$ procentilès) buvo $235(89 ; 728) \mathrm{min}$. Nustatyti šie rizikos veiksniai, kurie lèmé ilgesnę delsimo trukmę: gyvenimas kaime, lyginant su miestu (GS= $3,611 ; 95 \% \mathrm{PI}=1,311-9,955 ; \mathrm{p}=0,044)$, simptomu pasireiškimas naktį $(\mathrm{GS}=2,658 ; 95 \% \mathrm{PI}=0,998-$ 7,078; $\mathrm{p}=0,046)$, tikèjimas, jog atsiradę simptomai susiję su kita liga (GS=3,64; 95\% PI $=1,29-10,272$; $\mathrm{p}=0,012$ ). Išvados: pacientai, susirgę ūminiu miokardo infarktu, per ilgai nesikreipè medicinos pagalbos; nustatyti šie rizikos veiksniai, lemiantys ilgesnę delsimo trukmę: gyvenimas kaime, simptomų pasireiškimas naktį, tikejjimas, jog simptomai susiję su kita liga. Būtina gerinti visuomenès žinias apie ūminio miokardo infarkto klinikinius simptomus.

\section{Ivadas}

Europoje beveik pusę (47 proc.) mirties priežasčių lemia kardiovaskulinės (KV) ligos [1]. Nurodoma, jog Lietuva yra viena iš Europos šalių, kurioje mirtingumas nuo KV ligų iki $75 \mathrm{~m}$. amžiaus tiek tarp vyrų, tiek moterų užima pirmają vietą šalyje lyginant su kitomis priežastimis [1]. $2015 \mathrm{~m}$. Lietuvoje iš viso mire 41776 gyventojai, iš jų net 56,5 proc. nuo kraujotakos sistemos ligų [2], šis vidurkis ženkliai viršija Europos vidurkị. 2015 m. duomenimis, Lietuvoje miokardo infarkto (MI) dažnis, užregistruotas sveikatos priežiūros įstaigose, buvo 3,6 atvejo, tenkančio 1000 gyventojų, ir šis skaičius padidejo nuo 3,5 atvejo, tenkančio 1000 gyventojų $2014 \mathrm{~m}$ [3].

Pagrindinis ūminio miokardo infarkto (ŪMI) gydymo tikslas - kraujotakos atkūrimas pažeistoje raumens zonoje. Naudojami ịvairūs būdai miokardo perfuzijai atkurti, tačiau bene svarbiausias kriterijus geroms baigtims pasiekti yra kuo trumpesnis laikas, praejęs nuo simptomų pradžios iki kraujotakos atkūrimo [4]. Maždaug trečdalis mirčių nuo ŪMI ištinka per kelias valandas nuo simptomų pradžios ir dažniausiai dar nespejjus pasiekti ligoninès [5], o ankstyvas gydymas, ypač per pirmą , ,auksinę valandą“, lemia mažesnị miokardo raumens pažeidimo plotą, mirtingumą ir negalią [6]. Vis dèlto tyrimai rodo, jog laikas nuo simptomų pradžios iki kreipimosi ị gydymo ịstaigą svyruoja nuo kelių minučių iki kelių dienų [7].

Pagalbos delsimą susirgus ŪMI galima suskirstyti ị tris fazes: 1) sprendimo laikas - tai laikas nuo simptomų atsiradimo iki pasiryžimo ieškoti medicinos pagalbos, 2) laikas nuo pasiryžimo kviesti pagalbą iki pirmo medicininio kontakto, 3) hospitalizavimo laikas - tai laikas nuo pirmo medicininio kontakto iki atvykimo ì ligoninę ir pagalbos joje [8]. Bene svarbiausias periodas yra pirmasis, kadangi dažniausiai užtrunka ilgiausiai ir gali būti efektyviai sumažintas, jei pacientai identifikuotų ŪMI simptomus ir anksti kreiptųsi pagalbos [9]. Atlikta nemažai tyrimų, kuriais siekiama nustatyti galimas uždelsto kreipimosi priežastis įvairiose šalyse [7, 10 - 13], tačiau Lietuvoje tokio pobūdžio tyrimų rasti nepavyko.

Mūsų darbo tikslas - nustatyti kiek pacientai delsia nuo ŪMI simptomų atsiradimo iki sprendimo kreiptis medicinos pagalbos (sprendimo laikas), identifikuoti rizikos faktorius, susijusius su uždelstu kreipimusi medicinos pa- 
galbos, kad būtų galima kuo efektyviau sumažinti ši laiką.

\section{Tyrimo medžiaga ir metodai}

Atliktas prospektyvinis anketinis tyrimas individualiai apklausiant pacientus $2014 \mathrm{~m}$. vasario - $2015 \mathrm{~m}$. spalio mènesiais, gydytus Vilniaus universiteto ligoninès Santaros kliniku kardiologijos reanimacijos ir intensyvios terapijos skyriuje (KRITS). Apklausą sudarè originaliai tam paruoštas klausimynas. I tyrimą atsitiktinai buvo įtraukti pacientai, kuriems diagnozuotas ÜMI ir kurie hospitalizuoti KRITS dèl šios priežasties. Ligoniai buvo informuoti, kad apklausa anoniminè, paaiškinta tyrimo eiga ir tikslas, gautas sutikimas dalyvauti tyrime ir leidimas rinkti informaciją iš ligos istorijos tyrimo tikslams.

Informacijos rinkimas buvo suskirstytas $i \mathfrak{d u}$ etapus. Pirmuoju buvo vykdoma individuali žodinè kiekvieno paciento apklausa, renkama ši informacija: demografiniai duomenys, ligos pradžioje pasireiškę simptomai, informacija apie patị îvykị, hospitalizaciją, susirūpinimas ir domè-

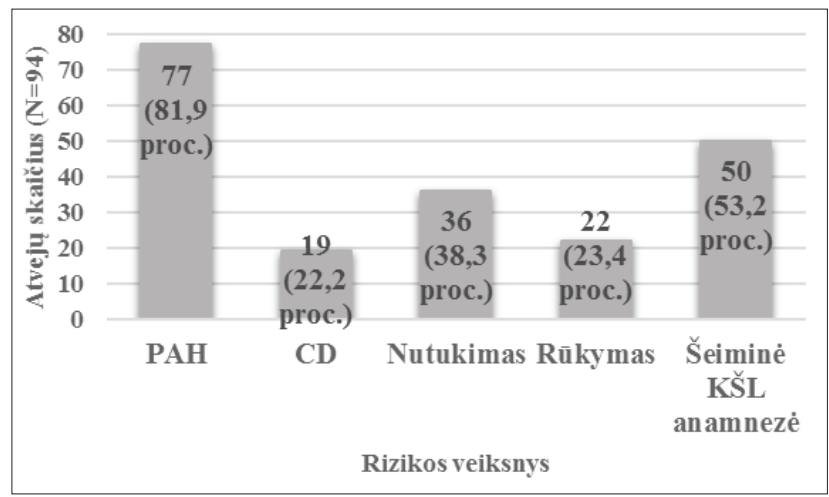

1 diagrama. Miokardo infarkto rizikos veiksnių dažnis tirtoje populiacijoje

PAH - pirmine arteriné hipertenzija; $C D$ - cukrinis diabetas; $K S \check{L}-$ koronarine širdies liga

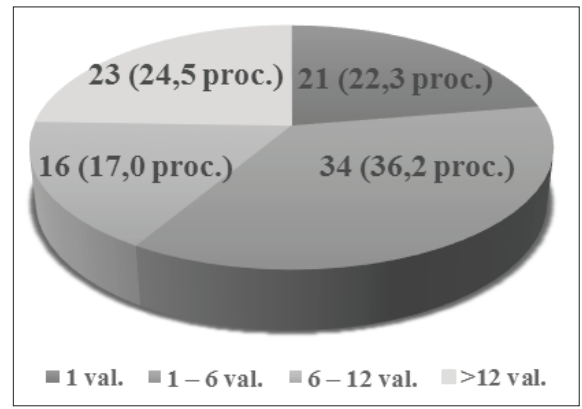

2 diagrama. Laiko, praejusio nuo miokardo infarkto simptomų atsiradimo iki sprendimo kreiptis medicinos pagalbos, pasiskirstymo dažnis. jimasis sveikata. Antruoju etapu buvo renkama informacija iš ligos istorijos: ŪMI charakteristika, medicininè anamnezè.

Apklausta 100 pacientų, iš kurių į galutinę analizę pateko 94. Jie buvo suskirstyti ị dvi grupes pagal laiką, kuris praejo nuo simptomų atsiradimo iki sprendimo kreiptis medicinos pagalbos: I $(\mathrm{N}=56)$ grupe $-\leq 6$ val., II $(\mathrm{N}=38)$ grupe - >6val. Duomenys apdoroti Microsoft Excel ir SPSS v.22 programomis. Lyginant kategorinius kintamuosius tarp 2 grupiu taikytas $\chi^{2}$ testas, kiekybinių duomenų tarp grupiu palyginimui naudotas Mann-Whitney testas neparametriniams kintamiesiems, siekiant išsiaiškinti rizikos veiksnius, lemiančius uždelstą kreipimąsi i gydymo įstaigą (I grupé vs. II grupè), buvo taikoma binarinè logistinè regresinè analizè. Kiekybiniams kintamiesiems pateikti vidurkiai ir standartiniai nuokrypiai, kategoriniams kintamiesiems - absoliutūs skaičiai $(\mathrm{N})$, procentinė jų išraiška (proc.), rizikos veiksniams nurodomas galimybiu santykis (GS) ir pasikliautinasis intervalas (PI), laiko intervalams mediana, 25 ir 75 procentilès. Rezultatai vertinti statistiškai patikimais, kai $\mathrm{p}<0,05$.

\section{Rezultatai}

Iš 100 apklaustų pacientų galutinèje analizèje dalyvavo 94 (94 proc.), 6 (6 proc.) pacientų duomenys ị analizę nebuvo įtraukti dèl nesugebejjimo nurodyti tikslaus simptomų atsiradimo laiko.

Pacientu amžiaus vidurkis $64 \pm 11$ metai, $40(42,6$ proc.) iš apklaustujų buvo moterys. Laiko, praejjusio nuo simptomų pradžios iki sprendimo kreiptis medicinos pagalbos paieškos mediana (25; 75 procentilès) buvo 235 (89; 728) min. MI rizikos veiksnių dažnis ir laiko, praejjusio nuo simptomų atsiradimo iki sprendimo kreiptis medicinos

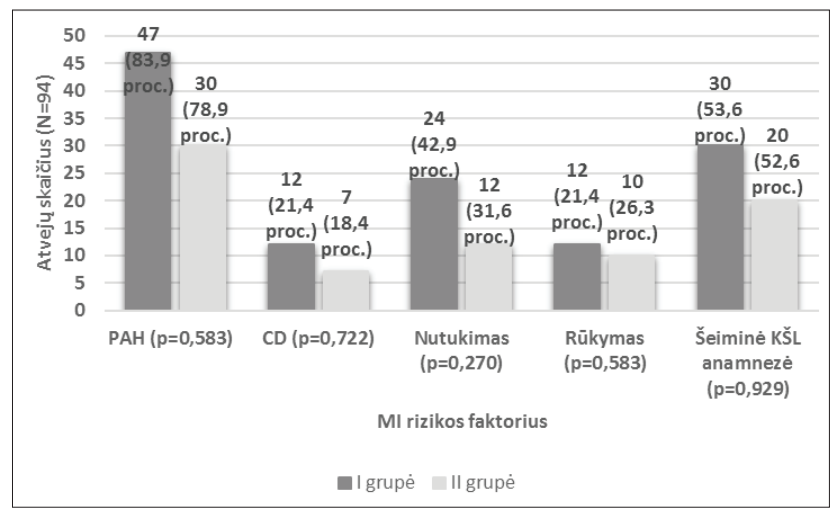

3 diagrama. Pagrindinių miokardo infarkto rizikos veiksnių dažnis I ir II grupejje.

$P A H$ - pirminé arteriné hipertenzija; $C D$ - cukrinis diabetas; $K \check{S} L$ - koronarine sirdies liga 
pagalbos, pasiskirstymas pateikti atitinkamai 1 ir 2 diagramose.

Laiko mediana ( $25 ; 75$ procentilès) nuo simptomų atsiradimo iki pirminès koronarinès intervencijos (PKI) atlikimo buvo $645(270 ; 1313)$ min. ir šis laikas buvo trumpesnis I grupejje lyginant su II (393 (174; 734) min. vs. 1298 (663; 1538) $\min ; \mathrm{p}=<0,001)$.

Amžiaus vidurkis tarp grupių nesiskyre $(64 \pm 10 \mathrm{~m}$. vs. $64 \pm 13$ m.; $p=0,882)$. I ir II grupių kokybiniai demografiniai duomenys ir MI rizikos veiksnių pasiskirstymo dažnis pateikti atitinkamai 1 lenteleje ir 3 diagramoje.

Dažniausias simptomas susirgus ÜMI abejose grupèse

1 lentelè. Kokybinių demografinių duomenų pasiskirstymas tarp grupių

\begin{tabular}{|l|c|c|c|c|c|}
\hline \multirow{2}{*}{$\begin{array}{l}\text { Demografiniai } \\
\text { duomenys }\end{array}$} & \multicolumn{2}{|c|}{ I grupe் (N=56) } & \multicolumn{2}{c|}{ II grupė (N=38) } & \multirow{2}{*}{$\begin{array}{c}\text { reikš- } \\
\text { mé }\end{array}$} \\
\cline { 2 - 5 } & $\mathbf{N}$ & Proc. & N & Proc. & 0,356 \\
\hline Moteriška lytis & 26 & 46,4 & 14 & 36,8 & 0,044 \\
\hline Gyvena kaime & 8 & 14,3 & 12 & 31,6 & 0,810 \\
\hline Gyvena vienas & 16 & 28,6 & 10 & 26,3 & 0,157 \\
\hline $\begin{array}{l}\text { Pagrindinis } \\
\text { išsilavinimas }\end{array}$ & 7 & 12,5 & 9 & 23,7 & 0,795 \\
\hline $\begin{array}{l}\text { Vidurinis išsila- } \\
\text { vinimas }\end{array}$ & 31 & 55,4 & 20 & 52,6 & 0,374 \\
\hline $\begin{array}{l}\text { Aukštasis išsi- } \\
\text { lavinimas }\end{array}$ & 18 & 32,1 & 9 & 23,7 & \\
\hline
\end{tabular}

2 lentelè. Simptomų dažnis susirgus ūminiu miokardo infarktu I ir II grupèse

\begin{tabular}{|c|c|c|c|c|c|c|c|}
\hline \multirow[t]{2}{*}{$\begin{array}{l}\text { Simpto- } \\
\text { mas }\end{array}$} & \multicolumn{2}{|c|}{$\begin{array}{l}\text { Iš viso } \\
(N=94)\end{array}$} & \multicolumn{2}{|c|}{$\begin{array}{l}\text { I grupe் } \\
(\mathrm{N}=56)\end{array}$} & \multicolumn{2}{|c|}{$\begin{array}{c}\text { II grupe } \\
(\mathbf{N}=\mathbf{3 8})\end{array}$} & \multirow{2}{*}{$\begin{array}{c}\mathbf{P} \\
\text { reikš- } \\
\text { me் }\end{array}$} \\
\hline & $\mathbf{N}$ & Proc. & $\mathbf{N}$ & Proc. & $\mathbf{N}$ & Proc. & \\
\hline $\begin{array}{l}\text { Krūtinės } \\
\text { skausmas }\end{array}$ & 84 & 89,4 & 49 & 87,5 & 35 & 92,1 & 0,631 \\
\hline $\begin{array}{l}\text { Skausmo } \\
\text { plitimas }\end{array}$ & 60 & 63,8 & 40 & 71,4 & 20 & 52,6 & 0,063 \\
\hline Dusulys & 46 & 48,9 & 28 & 50 & 18 & 47,4 & 0,802 \\
\hline Pykinimas & 29 & 30,9 & 19 & 33,9 & 10 & 26,3 & 0,433 \\
\hline Vèmimas & 15 & 16,0 & 11 & 19,6 & 4 & 10,5 & 0,236 \\
\hline Dispepsija & 23 & 24,5 & 14 & 25 & 9 & 23,7 & 0,884 \\
\hline $\begin{array}{l}\text { Prakaitavi- } \\
\text { mas }\end{array}$ & 52 & 55,3 & 33 & 58,9 & 19 & 50,0 & 0,393 \\
\hline $\begin{array}{l}\text { Baimé } \\
\text { numirti }\end{array}$ & 31 & 33,0 & 17 & 30,4 & 14 & 36,8 & 0,512 \\
\hline $\begin{array}{l}\text { Sąmonès } \\
\text { netekimas }\end{array}$ & 7 & 7,4 & 4 & 7,1 & 3 & 7,9 & 0,892 \\
\hline
\end{tabular}

buvo krūtinès skausmas ( $\mathrm{N}=49 ; 87,5$ proc. vs. $\mathrm{N}=35 ; 92,1$ proc.; $\mathrm{p}=0,631)$, rečiausias - sąmonès netekimas $(\mathrm{N}=4 ; 7,1$ proc. vs. $\mathrm{N}=3 ; 7,9$ proc.; $\mathrm{p}=0,892$ ). Simptomų pasireiškimo dažnio palyginimas tarp grupių pateiktas 2 lentelèje.

Nustatyti šie rizikos veiksniai, kurie lèmé ilgesnę trukmę nuo ÜMI simptomų atsiradimo iki sprendimo kreiptis medicinos pagalbos: gyvenimas kaime, lyginant su miestu $(\mathrm{GS}=3,611 ; 95 \% \mathrm{PI}=1,311-9,955 ; \mathrm{p}=0,044)$, simptomu pasireiškimas nakti (GS=2,658; 95\% $\mathrm{PI}=0,998$ - 7,078; $\mathrm{p}=0,046)$, tikejimas, jog atsiradę simptomai susiję su kita liga $(\mathrm{GS}=3,64 ; 95 \% \mathrm{PI}=1,29-10,272 ; \mathrm{p}=0,012)$. Visi tirti rizikos veiksniai pateikti 3 lentelejje.

3 lentelė. Rizikos veiksnių, lemiančių vèlesnę medicinos pagalbos paiešką (lyginant I ir II grupes), ịvertinimas GS - galimybiu santykis; PI - pasikliautinasis intervalas; $M I$ - miokardo infarktas; $C D$ - cukrinis diabetas; $P A H$ - pirminé arterine hipertenzija

\begin{tabular}{|l|c|c|}
\hline Rizikos veiksnys & $\begin{array}{c}\text { GS } \\
\text { (95 proc. PI) }\end{array}$ & $\begin{array}{c}\text { P reikš- } \\
\text { mé }\end{array}$ \\
\hline Moteriška lytis & $1,486(0,640-3,451)$ & 0,356 \\
\hline Amžius >65 metų & $0,967(0,424-2,205)$ & 0,936 \\
\hline Gyvenimas kaime & $3,611(1,311-9,955)$ & 0,044 \\
\hline $\begin{array}{l}\text { Pagrindinis išsilavi- } \\
\text { nimas }\end{array}$ & $2,172(0,731-6,457)$ & 0,157 \\
\hline $\begin{array}{l}\text { Gyvena vienas } \\
\text { CD }\end{array}$ & $0,893(0,354-2,254)$ & 0,810 \\
\hline $\begin{array}{l}\text { PAH } \\
\text { Krūtinės angina }\end{array}$ & $1,034(0,453-2,360)$ & $0,728(0,293-2,341)$ \\
\hline $\begin{array}{l}\text { Simptomai praside- } \\
\text { jo naktị }\end{array}$ & $2,658(0,998-7,078)$ & 0,046 \\
\hline $\begin{array}{l}\text { Prasidėjus simpto- } \\
\text { mams buvo vienas }\end{array}$ & $0,754(0,302-1,881)$ & 0,544 \\
\hline $\begin{array}{l}\text { Galvojo, jog susirgi- } \\
\text { mo priežastis kita }\end{array}$ & $3,64(1,29-10,272)$ & 0,012 \\
\hline $\begin{array}{l}\text { Anksčiau buvusi } \\
\text { kardiologinė inter- } \\
\text { vencija }\end{array}$ & $1,667(0,637-4,363)$ & 0,296 \\
\hline $\begin{array}{l}\text { Anksčiau persirgtas } \\
\text { MI }\end{array}$ & $1,621(0,577-4,555)$ & 0,375 \\
\hline $\begin{array}{l}\text { Nesidomi sveikata } \\
\text { informaciniuose } \\
\text { šaltiniuose }\end{array}$ & $0,609(0,225-1,646)$ & 0,325 \\
\hline 1 kartą per metus & $0,982(0,395-2,439)$ & 0,968 \\
\hline
\end{tabular}




\section{Diskusija}

„Auksinė valanda“, „laikas - raumuo“ - terminai, kurie dažnai akcentuojami kalbant apie ŪMI gydymą, tačiau tyrime nustatėme, jog tik kiek daugiau nei penktadalis pacientų $(\mathrm{N}=21 ; 22,3$ proc.) kreipèsi medicinos pagalbos per 1 val. nuo simptomų pradžios ir net 24,5 proc. delsè ilgiau nei 12 val. Akivaizdu, jog daugeliu ŪMI atvejų pagalbos paieška yra vèlyva, tačiau panašūs rezultatai identifikuojami ir kitose šalyse. Kinijoje atliktame tyrime nustatyta, jog ilgiau nei 1 valandą delsè 70,8 proc. [14], Graikijoje - 82 proc. [13] tiriamuju, Amerikoje mažiau nei 10 proc. pacientų i ligoninę atvyko per pirmą valandą nuo simptomų pradžios [15]. Delsimo laiko mediana (25; 75 procentilès) taip pat pasiskirsto nevienodai: mūsų atliktame tyrime 235 (89; 728) min., Graikijoje $210(120 ; 480)$ min. [13], Kinijoje $130(50-480)$ min. [14], Airijoje, vertinant visus ūminius koronarinius sindromus, 244 min [16]. ASSENT-3 PLUS tyrimas parode, jog kai kuriose šalyse šio laiko mediana trumpesnè: $60 \mathrm{~min}$. Prancūzijoje, $65 \mathrm{~min}$. Ispanijoje, 121 min. Jungtinejje Karalysteje, 74 min. Suomijoje, 55 min. Vokietijoje, $50 \mathrm{~min}$. Olandijoje, $42 \mathrm{~min}$. Kanadoje ir 50 min. Švedijoje [17], tačiau reikia paminèti, jog pastarajame tyrime buvo vertinamas delsimas iki pagalbos paieškos tik susirgus ŪMI su ST pakilimu ir tik tiems pacientams, kuriems buvo taikoma intraveninè trombolizè, kas lèmé rezultatų skirtumą tarp šio ir mūsų atlikto tyrimo.

Ivairios studijos skirtingai nurodo rizikos faktorius, lemiančius ilgesnę sprendimo kviestis medicininę pagalbą trukmę. $2015 \mathrm{~m}$. atliktoje apžvalgoje nurodoma, jog moteriška lytis ir vyresnis amžius yra rizikos faktoriai, kuriuos patvirtina daugelis tyrimų, tačiau kai kurios studijos statistiškai patikimų skirtumų tarp šių kintamųjų nenustato [18]. Tokias pačias išvadas galima padaryti ir apie mūsų tyrime identifikuotą rizikos veiksnị - simptomų pasireiškimą nakti, jis studijų buvo tiek patvirtintas [19], tiek paneigtas [20]. Kalbant apie kitus tyrime nustatytus rizikos veiksnius - gyvenimą kaime (didesnis atstumas iki gydymo įstaigos), simptomų tapatinimą su kita liga, tai daugelio studijų identifikuoti faktoriai, lemiantys vèlesnị medicinos pagalbos suteikimo laiką $[10,12]$. Tyrimuose nagrinejjami ir kiti galimi rizikos veiksniai: arterinè hipertenzija, cukrinis diabetas, rūkymas, krūtinès angina, buvęs miokardo infarktas, prieš tai atlikta koronarinè revaskuliarizacija ar širdies šuntavimo operacija, tačiau rezultatai dviprasmiški $[18$, 21]. Taigi, reikia nepamiršti, kad kiekvienoje šalyje pacientai turi tik jiems būdingas tradicijas, kultūrą, mentalitetą, kurie lemia požiūrị ne tik ị sveikatą, bet ir ị pagalbos paiešką susirgus, dèl to rizikos veiksniai, predisponuojantys pavèluotą kreipimąsi medicinos pagalbos, gali labai skirtis kiekvienoje valstybejje.
Šio tyrimo trūkumai - ištirta populiacija yra per maža norint nustatyti rizikos veiksnius Lietuvos mastu, be to, tokio pobūdžio analizè visuomet turi bene didžiausią minusą - pacientui reikia kuo tiksliau prisiminti, kada ŪMI simptomai prasidejo, kas gali būti labai subjektyvu. Tačiau tyrimas atskleidè, jog uždelstas kreipimasis medicinos pagalbos - aktuali problema, kuri, remiantis rezultatais, galètụ būti mažinama informuojant visuomenę apie ŪMI klinikinius simptomus, taip gerinant pacientų žinias ir padedant įtarti šią ligą bei užtikrinti ankstesnị kreipimąsi ị gydymo ìstaigą.

\section{Išvados}

1. Pacientai per ilgai delsè ir nesikreipé medicinos pagalbos susirgus ÜMI.

2. Identifikuoti šie rizikos faktoriai, lemiantys ilgesnę sprendimo kreiptis medicinos pagalbos trukmę: simptomy pasireiškimas nakti, gyvenimas kaime, simptomų tapatinimas su kita liga.

3. Būtina gerinti visuomenès žinias apie ŪMI klinikinius simptomus, siekiant ịtarti šią ligą ir anksčiau pradèti ieškoti medicinos pagalbos.

\section{Literatūra}

1. Nichols M, Townsend N, Luengo-Fernandez R, Leal J, Gray A, Scarborough P. et al. European Cardiovascular Disease Statistics 2012. European Heart Network, Brussels, European Society of Cardiology, Sophia Antipolis, 2012.

2. Higienos instituto Sveikatos informacijos centras. Mirties priežastys (išankstiniai duomenys) 2015. Vilnius: Lietuvos Respublikos Sveikatos apsaugos ministerija. Higienos instituto Sveikatos informacijos centras, 2016.

3. Higienos instituto Sveikatos informacijos centras. Lietuvos sveikatos statistika 2015. Vilnius: Lietuvos Respublikos Sveikatos apsaugos ministerija. Higienos instituto Sveikatos informacijos centras, 2016.

4. Bassand JP, Danchin N, Filippatos G, Gitt A, Hamm C, Silber S. et al. Implemention of reperfusion therapy in acute myocardial infarction. A policy statment from the European Society of Cardiology. Eur Heart J. 2005; 26:2733-2741.

https://doi.org/10.1093/eurhearti/ehi673

5. Chambless L, Keil U, Dobson A, Mähönen M, Kuulasmaa $\mathrm{K}$, Rajakangas AM. et al. Population versus clinical view of case fatality from acute coronary heart disease: results from the WHO MONICA Project 1985-1990. Multinational monitoring of trends and determinants in cardiovascular disease. Circulation 1997; 96(11): 3849-59.

https://doi.org/10.1161/01.CIR.96.11.3849

6. Boersma E, Maas AC, Deckers JW, Simoons ML. Early thrombolytic treatment in acute myocardial infarction: reappraisal of the golden hour. Lancet 1996; 348(9030):771-5. 
https://doi.org/10.1016/S0140-6736(96)02514-7

7. Jin H, Zhu S, Wei JW, Wang J, Liu M, Wu Y. et al. Factors associated with prehospital delays in the presentation of acute stroke in urban China. Stroke 2012; 43(2):362-70. https://doi.org/10.1161/STROKEAHA.111.623512

8. Moser DK, Kimble LP, Alberts MJ, Alonzo A, Croft JB, Dracup $\mathrm{K}$. et al. Reducing delay in seeking treatment by patients with acute coronary syndrome and stroke: a scientific statement from the American Heart Association Council on cardiovascular nursing and stroke council. Circulation 2006; 114(2):168-82. https://doi.org/10.1161/CIRCULATIONAHA.106.176040

9. Dracup K, McKinley S, Riegel B, Mieschke H, Doering LV, Moser DK. A nursing intervention to reduce prehospital delay in acute coronary syndrome: a randomized clinical trial. J Cardiovasc Nurs 2006; 21(3):186-93. https://doi.org/10.1097/00005082-200605000-00006

10. Ghazawy ER, Seedhom AE, Mahfouz EM. Predictors of delay in seeking health care among myocardial infarction patients, minia district, Egypt. Adv Prev Med 2015; 2015:342361 https://doi.org/10.1155/2015/342361

11. Banks AD, Dracup K. Factors associated with prolonged prehospital delay of African Americans with acute myocardial infarction. Am J Crit Care 2006; 15(2):149-57.

12. Nilsson G, Mooe T, Söderström L, Samuelsson E. Pre-hospital delay in patients with first time myocardial infarction: an observational study in a northern Swedish population. BMC Cardiovasc Disord 2016;16:93. https://doi.org/10.1186/s12872-016-0271-x

13. Pitsavos C, Kourlaba G, Panagiotakos DB, Stefanadis C; GREECS Study Investigators. Factors associated with delay in seeking health care for hospitalized patients with acute coronary syndromes: the GREECS study. Hellenic J Cardiol 2006; 47(6):329-36.

14. Wang X, Hsu LL. Treatment-seeking delays in patients with acute myocardial infarction and use of the emergency medical service. J Int Med Res. 2013; 41(1):231-8.

https://doi.org/10.1177/0300060512474567

15. Reeves MJ, Arora S, Broderick JP, Frankel M, Heinrich JP, Hickenbottom S. et al. Acute stroke care in the US: results from 4 pilot prototypes of the Paul Coverdell National Acute Stroke Registry. Stroke 2005; 36(6):1232-40. https://doi.org/10.1161/01.STR.0000165902.18021.5b

16. McKee G, Mooney M, O'Donnell S, O'Brien F, Biddle MJ, Moser DK. Multivariate analysis of predictors of prehospital delay in acute coronary syndrome. Int J Cardiol 2013; 168(3):2706-13. https://doi.org/10.1016/j.ijcard.2013.03.022

17. Welsh RC, Chang W, Goldstein P, Adgey J, Granger CB, Verheugt FW. et al. Time to treatment and the impact of a physician on prehospital management of acute ST elevation myocardial infarction: insights from the ASSENT-3 PLUS trial. Heart 2005; 91(11):1400-6.

https://doi.org/10.1136/hrt.2004.054510
18. Xie L, Huang SF, Hu YZ. Factors influencing prehospital patient delay in patients with acute myocardial infarction. Chinese Nursing Research 2015; 2:75-79.

https://doi.org/10.1016/j.cnre.2015.04.002

19. Guo J, Hua Q, Liu D. Factors related to patient delay time in patients with acute myocardial infarction ST segment elevation and essential hypertension. Am J Hypertens 2005; 18:219A220A.

https://doi.org/10.1016/j.amjhyper.2005.03.599

20. Sheifer SE, Rathore SS, Gersh BJ, Weinfurt KP, Oetgen WJ, Breall JA. et al. Time to presentation with acute myocardial infarction in the elderly: associations with race, sex, and socioeconomic characteristics. Circulation 2000; 102(14):1651-6. https://doi.org/10.1161/01.CIR.102.14.1651

21. Gärtner C, Walz L, Bauernschmitt E, Ladwig KH. The causes of prehospital delay in myocardial infarction. Dtsch Arztebl Int 2008; 105(15):286-91.

\section{DELAY IN SEEKING TREATMENT IN PATIENTS WITH ACUTE MYOCARDIAL INFARCTION}

\section{T. Tamošiūnas, R. Ruseckaitė, M. Laukytė, I. Bunevičiūtė}

Key words: acute myocardial infarction, prehospital delay, risk factors.

Summary

Acute myocardial infarction (AMI) is one of the main causes of death in Lithuania. Treatment success depends on time from symptoms onset to reperfusion. The main aim of our study was to investigate prehospital delay time and the influencing factors for prehospital delay in patients with AMI.

Methods and results: we interviewed 100 patients with AMI face-to-face. There were 94 patients in the final analysis. Patients were categorized into 2 groups: time from symptoms onset to decision to seek medical care $\leq 6$ hours ( ${ }^{\text {st }}$ group) and $>6$ hours ( II $^{\text {nd }}$ group). The median $\left(25^{\text {th }}, 75^{\text {th }}\right.$ procentiles $)$ prehospital delay time was $235(89 ; 728) \mathrm{min}$. Influencing factors for prehospital delay were symptoms onset at night $(\mathrm{OR}=2,658 ; 95 \% \mathrm{CI}=0,998-7,078$; $\mathrm{p}=0,046)$, thoughts their symptoms were associated with others diseases $(\mathrm{GS}=3,64 ; 95 \% \mathrm{CI}=1,29-10,272 ; \mathrm{p}=0,012)$, the living in rural area, compared with urban $(\mathrm{OR}=3,611 ; 95 \% \mathrm{CI}=1,311$ 9,955; $\mathrm{p}=0,044)$.

Conclusions: patients prehospital delay time was too long. The statistically significant risk factors for prehospital delay were symptoms onset at night, thoughts their symptoms were associated with others diseases, the living in rural area. It is necessary to improve public knowledge about AMI.

Correspondence to: buneviciute.igne@gmail.com

Gauta 2017-02-09 